\title{
Las imágenes y objetos en la escena expandida
}

\section{Images and objects in the expanded scene}

\author{
Silvia Elena Maldini
}




\section{Resumen}

La reflexión sobre la relación entre cuerpo y objeto en la escena en la era de la virtualidad dio origen en la Universidad Nacional de las Artes, en Argentina a la carrera de posgrado Especialización en Teatro de Objetos, interactividad y Nuevos Medios a la investigación que llamamos Cosidad, carnalidad y virtualidad. Cuerpos y objetos en la escena, editada en formato de libro físico en el 2018, con el apoyo de esa misma universidad. Este artículo retoma y amplía algunas de los conceptos de ese proyecto, los que muestran más claramente el recorrido que se inicia en los títeres, sigue con los objetos, el teatro objetual y el teatro visual. Reflexiona también sobre las nociones de cuerpo físico y cuerpo virtual, y su presencia en la escena compleja y expandida.

Palabras-claves: Teatro de Objeto; cuerpo físico; cuerpo virtual; títeres; video; Teatro visual

\section{Abstract}

The relation between body and object in the scene in the era of virtuality, has impulsed at the postgraduate career Specialization in Theater Objects, Interactivity and New Media, Universidad Nacional de las Artes, in Argentina, to the research that we name "Cosidad (as specificity of things), Carnality and Virtuality". Bodies and objects in the scene, published in print book (2018), with the support of the university. This paper takes up and extends some of the concepts of this project, those that show clearly the path that starts in the puppets, continues with the objects, the objectual theater and the visual theater. It also reflects on the physical body and virtual body notions and the presence in the complex and expanded scene.

Keywords: Theater of objects; physical body; virtual body; puppetry; video; Visual theater 
Lo material y lo virtual, la presencia y la ausencia, ficción y realidad, se presentan como rasgos esenciales en la escena intervenida por la imagen mediatizada, cuestionando la relación entre actor, objetos y espectador, en un espacio y un tiempo compartidos por ambos.

En este artículo se propuso una investigación sobre la interacción entre las imágenes tecnológicas, los cuerpos de los actores y los objetos en escena, tomando en cuenta los variados aspectos en los que dicha articulación se hace presente en Buenos Aires.

Se analizaron, en especial, las relaciones que surgen a partir de lo creado con la tecnología de las video-proyecciones en toda su extensión, desde las proyecciones más simples hasta complejos sistemas de pantallas, funciones interactivas, sistemas en red telemática, los nuevos soportes y herramientas que se actualizan día a día.

Por último, se reseña la experiencia artística personal en relación al video, tanto en instalaciones, como en lo performático.

Se concluye que la utilización de la tecnología y los llamados nuevos medios en la escena, forman parte de un cruce de lenguajes artísticos contemporáneos generadores de un nuevo tipo de performatividad. Una escena sin versus, en la que es posible crear obras que sean un encuentro entre seres (humanos, robots o avatares video proyectados), en un tiempo (real o diferido) y en un espacio (real o virtual).

\section{El encuentro entre objeto, cuerpo y video con la utilización de las nuevas tecnologías de la imagen}

\section{La materia luz}

Pepper's Ghost es el nombre de patente de un invento para la escena, que el Sr. J.H.Pepper inscribió en el Real Instituto de Londres en 1862. Lo inscribió dentro de la línea de "Fantasmagorías". El artilugio se componía de un vidrio en el que se mostraba al público la imagen de un actor, pero fantasmal. El actor, en realidad, estaba oculto debajo del escenario, frente a un espejo colocado en el ángulo exacto para reflejar la imagen al vidrio del escenario. Por supuesto, que el vidrio no era percibido por el público, solo la imagen, la fantasmagoría. Esta invención formaba parte de toda una corriente de ilusionismo teatral y también muchos magos de la época utilizaban técnicas similares para sacudir al público. Ya se habían utilizado con el mismo fin las linternas mágicas, el precedente a las proyecciones de diapositivas pero sin luz eléctrica. Con anterioridad, en las linternas mágicas, los fantasmas y demonios eran pintados sobre diapositivas de vidrio, y los espectadores se encontraban entre el equipo y la pantalla. En cambio, en la fantasmagoría, era la pantalla la que se interponía entre la máquina y el público. Así, al ocultar el proyector de la vista del público, se agregaba más realismo al show. El equivalente actual a estas fantasmagorías sería el holograma o el cine/tv en 3D. En este tipo de imágenes tecnológicas se pretende, como con el Pepper's Ghost, crear la ilusión de lo real, de la presencia. Sin embargo, en la actualidad, se sigue utilizando el artilugio mecánico, combinado con tecnología actual. Se usó en un concierto para revivir al fallecido rapero Tupac Shakur, actuando en vivo con otros músicos y cantando con el público (2012). Se trató de un artificio 
basado en la utilización de un sistema de espejos que refleja la imagen. La patente es propiedad de Musion Systems Ltd., compañía inglesa que ya en 2006 la utilizó con Gorrillaz y Madonna.

Es algo corriente y ya histórico el hecho de ver proyecciones de video o de diapositivas en las obras de teatro y en los recitales de música, aunque en general se trata de imágenes proyectadas en pantallas o sistemas de pantallas (video Wall) rectangulares, que remiten al cine y a la TV. El hecho de mantener el rectángulo de la pantalla hace que no se produzca la ilusión de lo real, son imágenes que más bien remiten al cine. A partir de la invención del cine y desde que es incorporado a la escena teatral, la tecnología y el teatro comienzan una relación con muchas variantes y profundidades. Erwin Piscator (Alemania, 1893-1966) es uno de los primeros directores teatrales en introducir el cine en sus espectáculos: proyecciones de noticiarios, de documentos, y también secuencias filmadas por los actores mismos. Piscator utilizó la percepción del espectador a su favor, creando nuevas producciones con contenido y puntos de vista movilizantes. Apelaba al uso del cine dentro del espacio teatral, dividiendo el espacio, marcando planos simbólicos bien diferentes. Por un lado estaba el cuerpo físico del actor y por el otro lado, un cuerpo virtual que correspondía a la proyección del cine. Así lograba acentuar el distanciamiento entre la realidad y la ficción que se producía en la escena del teatro épico. Más tarde, el checo Josef Svoboda también utilizó cine y luego video en sus obras, en función de brindar al espectador visiones ampliadas de la escena real. Ambos utilizaban en sus producciones el aspecto rectangular de la pantalla, se apoyaban en las imágenes proyectadas para crear algún tipo de relación con lo que sucediera en la escena real.

Las tecnologías de la información y de la comunicación forman parte de la vida cotidiana de los seres humanos del siglo XXI. A medida que aparecen nuevas tecnologías, cambian también los significados y las nuevas estructuras de percepción llevan a nuevas maneras de ver. El espectador actual forma parte de esta era de las pantallas $y$, por lo tanto, el artista también. El arte se interesa por esos cambios tecnológicos de los modos de producción y de las relaciones humanas, poniendo en perspectiva los efectos y obligando a tomar conciencia de ellos y construyendo la obra junto al espectador en ese "estado de encuentro". Al decir de Nicolas Bourriaud (2006, pág. 17): "El arte es un estado de encuentro", refiriéndose a las prácticas artísticas contemporáneas en las que percibe "una forma de arte donde la intersubjetividad forma el sustrato y que toma por tema central el estar-juntos, el 'encuentro' entre espectador y obra, la elaboración colectiva del sentido". Todo tipo de superficies y objetos y cuerpos son susceptibles de ser atravesados por proyecciones. El juego de combinaciones es inmenso. La variedad de soportes también es extensa en posibilidades: pantallas de tela, pantallas semitransparentes, pantallas de leds, videowalls, monitores, computadoras, smartphones, etc. Hay una multiplicidad de materias significantes que confluyen en la puesta en escena.

\section{La materia visual}

El teatro visual según la definición de Julio Abellán (2006, pág.109) "correspondería a las dramaturgias que se plantean la elaboración de un discurso expresable 
exclusiva o primordialmente en imágenes y que utilizan para su traducción escénica los lenguajes más visuales de las artes de la representación".

Se trata de una práctica escénica contemporánea que recoge la transdisciplinariedad de las artes escénicas y además incorpora lenguajes provenientes de todos los campos de las artes visuales y de la comunicación, resultando así, "un amplio abanico de manifestaciones escénicas de modalidades, contenidos, formatos y estilos muy diversos".

Las vanguardias históricas del siglo XX vislumbraron un teatro visual con el que golpear y desestructurar al público. Como algunos textos extravagantes de los surrealistas, dadaístas y futuristas, como los de Henry Rousseau, Antonin Artaud, Guillaume Apollinaire, Tristan Tzara, Pablo Picasso.

Por otra parte, Gordon Craig con los dibujos del proyecto llamado La escalera, Oskar Schlemmer, artista abstracto del movimiento Bauhaus, también aportaron a un nuevo y abierto panorama escénico visual e imaginativo.

Textos y dibujos que expresan mundos visuales y rítmicos fuera de lo cotidiano y de las convenciones escénicas que indican una ruptura hacia otro tipo de teatro, de pura invención.

También se encuentra como herencia de comienzos del siglo $X X$ al teatro ruso de la revolución, junto con el cubo futurismo y el constructivismo como herramienta para la imaginación, no para la ilusión, como es el caso de Meyerhold. También el director de cine Eisenstein, quien tuvo una etapa teatral en sus comienzos y planteaba la idea de utilizar imágenes contundentes como puñetazos, procedimiento que luego lo llevará a un elemento esencial del lenguaje cinematográfico: el montaje.

Luego, con la Segunda Guerra Mundial y el nazismo, el escenario de la creación moderna se traslada a Estados Unidos con artistas llegados de todas partes que desarrollaron un arte conceptual y un arte de acción emparentado con las primeras vanguardias europeas. Todo confluiría en las prácticas artísticas de los años sesenta, que fusionaron el arte conceptual, la música aleatoria, la nueva danza, teatro, medios de comunicación, la instalación, el arte de acción, prefigurando el teatro visual del futuro.

Estos procesos creativos contaminaron el teatro más joven y no oficial con un gran impulso de renovación y apertura para las artes escénicas.

El teatro visual piensa en imágenes, no traduce en imágenes, escapa de la creación escénica entendida exclusivamente como puesta en escena de las escrituras dramáticas, incluye todas las modalidades de representación escénica dramática y no dramática, con elementos de la danza, del teatro de texto, del teatro gestual, del circo, de los audiovisuales, de la música, de los títeres y los objetos.

El teatro visual propiamente dicho se manifiesta en la década de los setenta y alcanza su apogeo en los ochenta del siglo XX. Algunos artistas pioneros fueron Robert Wilson, Meredith Monk, Laurie Anderson, Robert Lépage, John Cage, Tadeusz Kantor, Mario Martone, Jan Fabre, Pina Bausch, Studio Hinderik, La fura dels baus, y en Italia lo que se conoció como la nuova spettacolarità: Societas Raffaello Sanzio, Falso Movimento o Giorgio Barberio Corsetti.

También se hereda el aporte de los textos teóricos de artistas consagrados en el campo del teatro, el cine y las artes visuales como Andrei Tarkovski, Marcel Duchamp, Heiner Müller, Eduardo Pavlovsky y Mauricio Kartun. 
En Argentina, en las décadas del ochenta y noventa hubo un teatro pionero en la experimentación con la imagen, tanto visual como objetual, que se hizo presente en los trabajos de artistas como Javier Margulis, Ricardo Bartis y El Periférico de Objetos.

\section{La materia tiempo}

En la presentación virtual de los actores y objetos existe un nuevo factor a tener en cuenta: el tiempo. La proyección puede suceder en un tiempo diferido, logrado con imágenes previamente grabadas o en tiempo real, a partir de la transmisión en directo.

Muchas puestas en escena están trabajando con lo telemático, es decir con actores que no están en carne y hueso en el escenario, sino que se encuentran en otro lugar geográfico y actúan en la obra por medio de tecnologías asociadas a internet, que permiten la comunicación a distancia en tiempo presente real. Tecnologías como video-conferencia, chat, y también con la ya tradicional transmisión de cámaras en circuito cerrado. La cualidad de lo real en el teatro, pasa a ser considerado no como un espacio material compartido, sino como tiempo real compartido entre varias personas. Al tiempo se le agrega el adjetivo "real". Estos cambios de paradigmas en la construcción dramática, referidas a las nociones de tiempo y espacio, afectan a todas las partes intervinientes en la escena.

Para el espectador el cambio pasa por una nueva forma de presenciar las obras. Una forma más activa y comprometida con lo multisensorial. El teórico Philip Auslander (1999), profesor de la Universidad de Georgia Tech y autoridad en el tema cultura de masas y mediatización de eventos, plantea que el versus "en vivo/mediatizado" se encuentra superado por el hecho de que en el teatro actual ambas posibilidades se pueden mezclar y co-existir. El eje presencia-ausencia, central desde que la escena se cruza con los otros lenguajes artísticos y a los medios tecnológicos contemporáneos. La presencia del cuerpo frente a la ausencia de un cuerpo mediatizado. ¿Deja de ser teatro cuando el encuentro de dos personajes se produce entre un individuo actor y un individuo proyectado? Esta cuestión presencia-ausencia es crucial en la relación de la escena con la imagen mediatizada. Justamente este debate o discusión en torno a la definición de lo que es y lo que no es teatro, se enfoca en las cualidades físicas, sensoriales, comunicacionales del cuerpo del actor por oposición al cuerpo invisible que se brinda en las imágenes proyectadas o mediatizadas.

La percepción del espectador es totalmente distinta cuando se presencia una obra de cuerpos y objetos a cuando se presencia imágenes que representan esas realidades. La imagen que es proyección carece de realidad; es luz, sombra y un proyector. Siempre es algo perfecto, acabado en sí mismo, situado en un tiempo que no es el presente del espectador y está expuesta para ser vista. Son como ilusiones que relajan y complacen psicológicamente porque son simplemente eso que se ve, no hay más nada que lo que se percibe. En cambio, los objetos materiales y el cuerpo del actor en escena despiertan en el público otro tipo de emociones. Se puede palpar la realidad del tiempo presente compartido con el espectador, la respiración, el peso, las medidas, lo tangible. La imagen tecnológica es etérea e inmaterial.

El desarrollo tecnológico, corriendo a una velocidad excepcional lleva a pensar que las imágenes funcionan solas, y que el papel del artista contemporáneo es revelar 
las interrelaciones que suceden entre las tecnologías y lo humano. Estas reflexiones acerca de la imagen complejizan aún más la interacción existente entre las artes en general y las multimediales en particular, con la escena teatral y lleva a una profundización de las funciones posibles de las imágenes proyectadas en relación a los cuerpos y los objetos escénicos. Desde ya que lo escénico no necesita para existir de ningún tipo de mediatización.

Para artistas que realizan performances, lo digital ha contribuido con todo tipo de desarrollos tecnológicos a la exploración del cuerpo humano, sometiéndolo a experimentaciones, llevándolo a límites impensados. Tal es el caso de los artistas que trabajan con su propio cuerpo, con prótesis, exoesqueletos o cirugías, adhiriendo a estéticas cyborg o de tecnofilia. Puestas en escena pensadas para actores digitales jugarían con la desmaterialización y virtualización del cuerpo humano, ya que la imagen proyectada carece de aura y está liberada de su realidad. Es una toma de posición en que lo virtual y lo humano no se diferenciarían entre sí (Cornago Bernal, 2004). Como una nueva manera de percibir la subjetividad contemporánea en un mundo no corpóreo invadido por las nuevas tecnologías.

\section{La imagen proyectada en función de lo escénico}

Desde los años 90 el mundo en general y, por lo tanto, el artístico se vio signado por varios cambios como la caída del muro de Berlín y las posteriores consecuencias sociopolíticas, así como también por avances tecnológicos como el uso masivo de las computadoras personales y el desarrollo de internet.

A nivel artístico, el siglo actual recibe desde las artes visuales una herencia rica en transformaciones que proviene de las vanguardias del siglo XX. Una herencia caracterizada por el llamado giro conceptual, la crítica a las instituciones, el cambio en la relación artista-espectador, la importancia de las reproducciones, copias y citas, y una tendencia a salirse de sus límites buscando de unir el arte con la vida.

Nicolás Bourriaud (2006) reflexiona sobre la imagen contemporánea caracterizándola por su poder generador: ya no es una huella (retroactiva), sino un programa (activo), es el resultado de algoritmos y su forma no siempre concluye en una presencia humana. El desarrollo tecnológico, corriendo a una velocidad excepcional lleva a pensar que las imágenes funcionan solas, y que el papel del artista contemporáneo es revelar las interrelaciones que suceden entre las tecnologías y lo humano.

Estas reflexiones acerca de la imagen complejizan aún más la interacción existente entre las artes en general y las multimediales en particular, con la escena teatral y lleva a una profundización de las funciones posibles de las imágenes proyectadas en relación a los cuerpos y los objetos escénicos.

Al hablar de las artes escénicas que inscriben cuestiones mediáticas, Mónica Berman (2013), expresa que cuando se utiliza la mediatización se modifican las relaciones de espacio, de tiempo, de los cuerpos, entre otras. Pronto aparecen las dudas, las interrogaciones acerca de cuánto modificará la escena una incursión en los medios tecnológicos. Se generan cuestiones de definiciones respecto a si la obra mediatizada es un híbrido o es una obra mixta, o si deja de existir como fenómeno cara a cara. En realidad, la incursión o utilización de dispositivos y medios tecnoló- 
gicos no implica que la escena esté sobre el medio o viceversa. Sino que existe un intercambio entre los dos universos, a través de cruces de lenguajes diferentes que van conformando una obra nueva.

Por supuesto que lo escénico no necesita para existir de ningún tipo de mediatización. A pesar de eso, en ciertas obras se vuelve necesaria cierta mediatización y sin esa tecnología no podrían acontecer situaciones esenciales. Como es el caso de la presencia virtual de un personaje a la distancia. O el caso de personajes que existen solo en la pantalla del televisor, siendo entonces un elemento que constituye la escena. Sin ese televisor el personaje no existe. $Y$ a pesar de que no está en carne y hueso, nadie puede negar que el personaje está presente en la obra y que el espectador lo percibe como un actor o personaje más de la obra, aun siendo un simulacro de lo real.

Todo tipo de superficies y objetos y cuerpos son susceptibles de ser atravesados por proyecciones. El juego de combinaciones es inmenso. La variedad de soportes también es extensa en posibilidades: pantallas de tela, pantallas semitransparentes, pantallas de leds, videowalls, monitores, computadoras, smartphones, etc. Hay una multiplicidad de materias significantes que confluyen en la puesta en escena.

Las obsesiones, las fantasías, las apariciones fantasmales, o los recuerdos pueden encontrar en las proyecciones de video un medio perfecto para ser plasmados como signos en una obra escénica. También las imágenes abstractas o surreales que escapan a la representación naturalista. Este conjunto de imágenes sugerentes produce un cambio perceptivo en la escena teatral, induce a la contemplación artística, a una construcción de sentido más libre, más personal y más fragmentado por parte del espectador.

En el teatro, el uso de las tecnologías sigue llamando mucho la atención. Se las sigue pensando como novedades a la manera de efectos especiales y por eso mismo aún resulta complicado encontrar obras en las que la tecnología incorporada sea asimilada con naturalidad y no resulte visible o llamativa al espectador. Los dispositivos, a pesar de su uso cada vez más habitual, aún conservan cierta fascinación futurista que puede hacer fracasar la consistencia de una obra escénica. La problemática de una interfaz natural y amigable es un hecho que se extiende a todos los ámbitos en los que hay un dispositivo y un usuario, esto va desde el diseño hasta el arte en general. En la habilidad y creatividad de los artistas-tecnólogos está encontrar el camino certero hacia los espectadores.

\section{El nuevo cuerpo, la realidad aumentada}

La realidad aumentada en relación al teatro y las nuevas tecnologías permitiría que la puesta en escena se ampliara de una manera hiperrealista, como una comunión entre la realidad aparente y la realidad virtual mediatizada, todo conectado a su vez a la red, como capas de realidad intercomunicadas.

Hay muchas experiencias escénicas en las que cuerpo físico de los actores se combina con la proyección del video de cuerpos virtuales o avatares, con el empleo de las nuevas tecnologías para crear escenografías y entornos digitales en busca de lo inmersivo y de la extensión del cuerpo del actor por medio de una hibridación de lo real y lo virtual. 
El cuerpo del espectador y el cuerpo del actor atraviesan en estos casos el cambio más radical de la historia del espectáculo.

En 1998, Robert Wilson estrenó Monsters of Gace 1.0. Se trataba de una ópera digital con música de Philip Glass y poemas del místico sufí Rumi. El público asistía con gafas 3D, a una obra protagonizada por actores digitales, en proyección 3D. Duraba 68 minutos y la parte animada fue hecha por 20 animadores durante un año, con un alto costo económico. Wilson perdió en seguida el control sobre la parte animada, y no se sintió satisfecho con el resultado, recibiendo además muy malas críticas.

Para artistas que realizan performances, lo digital ha contribuido con todo tipo de desarrollos tecnológicos a la exploración del cuerpo humano, sometiéndolo a experimentaciones, llevándolo a límites impensados. Tal es el caso de los artistas que trabajan con su propio cuerpo, con prótesis, exoesqueletos o cirugías, adhiriendo a estéticas cyborg o de tecnofilia. Puestas en escena pensadas para actores digitales jugarían con la desmaterialización y virtualización del cuerpo humano, ya que la imagen proyectada carece de aura y está liberada de su realidad. Es una toma de posición en que lo virtual y lo humano no se diferenciarían entre sí (Cornago Bernal, 2004). Como una nueva manera de percibir la subjetividad contemporánea en un mundo no corpóreo invadido por las nuevas tecnologías.

El extremo más optimista del uso de la tecnología en el teatro es la de utilizar la técnica del holograma para hacer realidad ciertas fantasías escénicas no corpóreas. El holograma permitiría un mundo virtual con la potencialidad de representar ciertas obras del pasado aggiornandolas con tecnologías digitales. Esto permitiría un teatro tecnológico liberado de la arquitectura teatral, en la que un grupo de artistas con tan solo unas computadoras, unos parlantes y un proyector podrían armar sus obras en cualquier lugar del planeta.

\section{Experiencia personal de video en función performática}

María Magdalena o la salvación (2015-2017). De Marguerite Yourcenar, dirigida por Ana Alvarado. Video arte: Silvia Maldini. Estrenada el 3 de mayo de 2015 en el teatro Patio de Actores. Bueno Aires.

El texto de Yourcenar despliega un universo de imágenes muy extenso y profundo y lo hace a través del personaje de María Magdalena. En la obra dirigida por Ana Alvarado, María Magdalena escapa al estereotipo iconográfico post Concilio de Trento, aunque toma como punto de partida para la generación de lo visual, a los variados atributos que se le adjudican al personaje. Estos son el frasco de perfume con el que ungió a Jesús, que puede ser también depósito de vida y espiritualidad; el libro que acompaña sus meditaciones y simboliza ciencia y sabiduría; el paisaje de la naturaleza que implica un retiro a la meditación; el espejo con un significado igualmente doble y contrario, porque remite a Magdalena como emblema de la lujuria y del orgullo y al mismo tiempo proporciona el reflejo, y así representa Prudencia, Verdad y el conocimiento de sí mismo. El uso de video proyecciones en esta obra, cumple con varias funciones que se entremezclan. No estamos ante una "escenografía virtual" en la que el video sustituye al fondo escenográfico. Se suceden distintas relaciones entre 
los videos y el personaje de María Magdalena (interpretado por Julieta Alfonso). Por momentos la actriz interactúa con el video y el cuerpo se ve integrado con el fondo, creando una perspectiva nueva. Otras veces la relación tiene una función subjetiva que sirve para representar los pensamientos o sensaciones del personaje.

En un momento central de la obra, las imágenes de video cobran un carácter de pieza de videoarte casi autónoma. Se trata de una función sinestésica del video, donde no hay una conexión directa entre imagen y acción escénica, sino una relación más vinculada a la retórica y a lo estilístico. Es cuando los personajes de María Magdalena y Marguerite Yourcenar se relacionan entre sí en una acción de lectura del texto dramatúrgico. En este fragmento, el video despliega imágenes documentales que crean otro tipo de relación dialéctica con la acción escénica. Se pueden ver fotos de torturas infligidas a mujeres de distintas épocas y culturas, también fotos de modas, de cirugías estéticas. Es la historia de los tormentos y manipulaciones sobre el cuerpo de la mujer. Junto con estas mujeres torturadas siempre aparece en el centro de la pantalla, la imagen de una mujer en movimiento, despojada de todos esos estilos y modas, esencial y atemporal, la imagen de todas las mujeres libres. En otra escena, una imagen se revela lentamente desde la parte inferior hacia arriba, hasta abarcar todo el fondo de la escena. Es La última cena de Leonardo Da Vinci, pero intervenida hasta vaciarla de personajes y tomar coincidentemente la misma escala que la pintura original. La imagen se repite como leitmotiv a lo largo de la obra.

La narración de Yourcenar ubica a una María Magdalena que cuenta la historia desde el presente y es así que hacia el final de la obra, las imágenes de video muestran un paisaje urbano del presente, casi arrancando al espectador del ensueño surreal y atemporal que venía vivenciando en las imágenes precedentes. En los últimos minutos de la obra, se suma la presencia de los espejos, en forma de un dispositivo tecnológico con cámaras que registran la acción en vivo y se integran a la escena mediatizando al público y fusionándolo con los personajes de la obra. Las proyecciones de video también funcionan como espejo en algún sentido, porque reflejan a los personajes desde distintos puntos de vista. María Magdalena le ofrece un espejo de mano a Marguerite/Títere (interpretado por Omayra Martínez Garzón), a la autora que le dio vida en la obra. Marguerite se mira ella misma en el espejo y a la vez, la invita a María Magdalena a mirarse. Comparten el hecho de reflejarse y todo lo que eso implica. María Magdalena se aleja para seguir mirándose de cuerpo entero. Es allí cuando el público se funde con la imagen del personaje y los dos mundos se hacen presentes en una misma proyección.

\section{Referencia}

ALVARADO, Ana (comp) Cosidad, Carnalidad y Virtualidad, Cuerpos y objetos en la escena. Buenos Aires: UNA Artes Dramáticas, La Imprenta Ya, Munro, 2018.

AUSLANDER, Philip. Liveness: Performance in a Mediatized Culture. UK: Routledge, 1999. 
ABUÍN GONZÁLEZ, Anxo. Teatro Y Nuevas Tecnologías: Conceptos Básicos. Edición digital en Signa: revista de la Asociación Española de Semiótica, núm. 17, 2008. Madrid, Centro de Investigación de Semiótica Literaria, Teatral y Nuevas Tecnologías

ABELLAN, Joan. El teatro visual. Barcelona: Institut del Teatre de Barcelona, Artea. Investigación y creación escénica, 2006.

BERMAN, Monica Teatro en el Borde. La ruptura de los verosímiles. Buenos Aires: Editorial Biblos, 2013.

BOURRIAUD, Nicolas. Estética relacional. Buenos Aires: Adriana Hidalgo, editora, 2006.

CAUSEY, Matthew. Theatre and Performance in Digital Culture: From Simulation to Embeddedness. UK: Routledge, 2006.

CORNAGO BERNAL, Oscar. «El cuerpo invisible: teatro y tecnologías de la imagen», Arbor (CSIC, Madrid) 699-700, 2004, p. 595-610.

MALDINI, Silvia. Multimedia, art media o más allá de los media en: Revista digital Territorio Teatral, N8, Dossier 1. Multimedia y Teatro, 2012.

MAURIN, Frederic. Spectral Spectacle. Puck. N 9. Images Virtuelles. France, Edition Institut International de la Marionnette, 1996.

Recibido en: $12 / 07 / 2018$

Aprobado en: 19/07/2018 